\title{
ESPINHAÇO - QUO VADIS ? \\ (ONDE ESTÁ? - AONDE VAI?) \\ A EVOLUÇÃO DOS CONHECIMENTOS SOBRE A CORDILHEIRA DO ESPINHAÇO MERIDIONAL EM MINAS GERAIS ENTRE 1979 E 1995
}

\author{
Friedrich E. Renger (*) \& Luiz Guilherme Knauer (**)
}

\begin{abstract}
In this paper a brief review is given of master and doctoral thesis as well of articles published during the last 16 years, concerning the geology of the Serra do Espinhaço in Minas Gerais, Brazil. The different proposals of a subdivision of the Archean basement and sedimentary sequences of Pre-Espinhaço age are reviewed. The existing geochronological data are insufficient for a complete understanding of these units. The Espinhaço rift started its evolution about $1800 \mathrm{Ma}$ ago with continental sediments with intercalation of acidic and basic volcanics evolving in the upper part of the sequence to shallow marine sedimentation.

Aspects of stratigraphy and sedimentology of the Espinhaço Supergroup as well as those of structural and economic geology are briefly discussed. Diamonds washed in the Sopa-Brumadinho conglomerates and in alluvials remains the principal mineral resource as about 160 years ago predicted by L.W. von Eschwege. In recent years exploration work was successful to identify the gold deposit at Riacho dos Machados in the northern extension of the Serra do Espinhaço.

A chapter resumes the geodymamic models presented during the considered period. Finally, suggestions for future investigations are listed.
\end{abstract}

\section{INTRODUÇÃO}

Nos 16 anos passados desde a realização do I Simpósio de Geologia de Minas Gerais, o avanço no conhecimento geológico sobre a Cordilheira do Espinhaço em seu setor mineiro foi, ainda que irregular, bastante acelerado e profícuo. Os resultados destas pesquisas podem ser encontrados em mais de sessenta teses de Mestrado ou doutorado e em mais de duzentos trabalhos publicados em congressos, simpósios e revistas especializadas, internacionais e nacionais (ver relação em Souza \& Martins1995; neste volume).

Após um período de mapeamento regional com inventário das principais unidades geológicas, ocorre uma clara tendência à especialização com pesquisas de maior detalhe em vários campos da geologia, notadamente em estratigrafia/sedimentologia, geologia estrutural e geologia econômica. Ultimamente, alguns trabalhos têm dado ênfase à investigação geocronológica, assim como aqueles abordando modelos de evolução geológica/geodinâmica para os terrenos da Serra do Espinhaço, especialmente de seu setor meridional.

Mapeamento geológico sistemático em escala 1:25.000 foi levado a efeito principalmente em áreas das folhas 1:100.000 Diamantina, Presidente Kubitschek e Serro, através de convênio envolvendo a UFMG, o DNPM e a CPRM, e cuja metodologia tem sido aproveitada para a realização de uma série de trabalhos de graduação no Centro de Geologia Eschwege (que envolvem alunos de diversas escolas brasileiras). Recentemente, destaca-se o chamado "Projeto Espinhaço" (Convênio Secretaria de Estado dos Recursos Minerais, Hídricos e Energéticos/ COMIG/ UFMG/ IGC), responsável pela cartografia geológica de praticamente toda a Serra do Espinhaço em Minas Gerais na escala de 1:100.000 (do qual uma rápida síntese pode ser encontrada no Relatório da Folha Serro, Knauer \& Grossi Sad 1995).

No trabalho ora apresentado serão discutidos alguns dos resultados das investigações resultantes deste enorme esforço de pesquisa, em especial daquelas publicadas a partir de 1979. Para referências bibliográficas mais detalhadas, anteriores a esta data, sugere-se a consulta de Renger (1979), Uhlein (1991) e Almeida-Abreu (1993), bem como aos 23 relatórios do Projeto Espinhaço.

\section{OS MODELOS ESTRATIGRÁFICOS}

O modelo básico utilizado na discussão a seguir e que representa o desenvolvimento das idéias iniciais de Pflug (1968) e Pflug \& Renger (1973), é aquele proposto por Schöll \& Fogaça (1979) para a região central da Serra do Espinhaço Meridional. O arranjo então sugerido reconhece as seguintes unidades principais: Supergrupo Pré-Rio das Velhas (terrenos gnáissicos-graníticos- migmatíticos de idade arqueana), Supergrupo Rio das Velhas (sequiência vulcanosedimentar de baixo grau metamórfico de provável idade arqueana) e Supergrupo Espinhaço, de idade Proterozóica, constituído pelas oito formações definidas por Pflug (1968). Schöll \& Fogaça (1979) propõem, por outro lado, a subdivisão das duas formações mais basais em seis unidades informais de mapeamento, designadas de níveis A, B e C (Formação São João da Chapada) e D, E e F (Formação Sopa-Brumadinho).

Deve-se notar que este modelo não se estende para oeste, onde afloram rochas neoproterozóicas dos grupos Macaúbas e Bambuí (englobados por Pflug \& Renger 


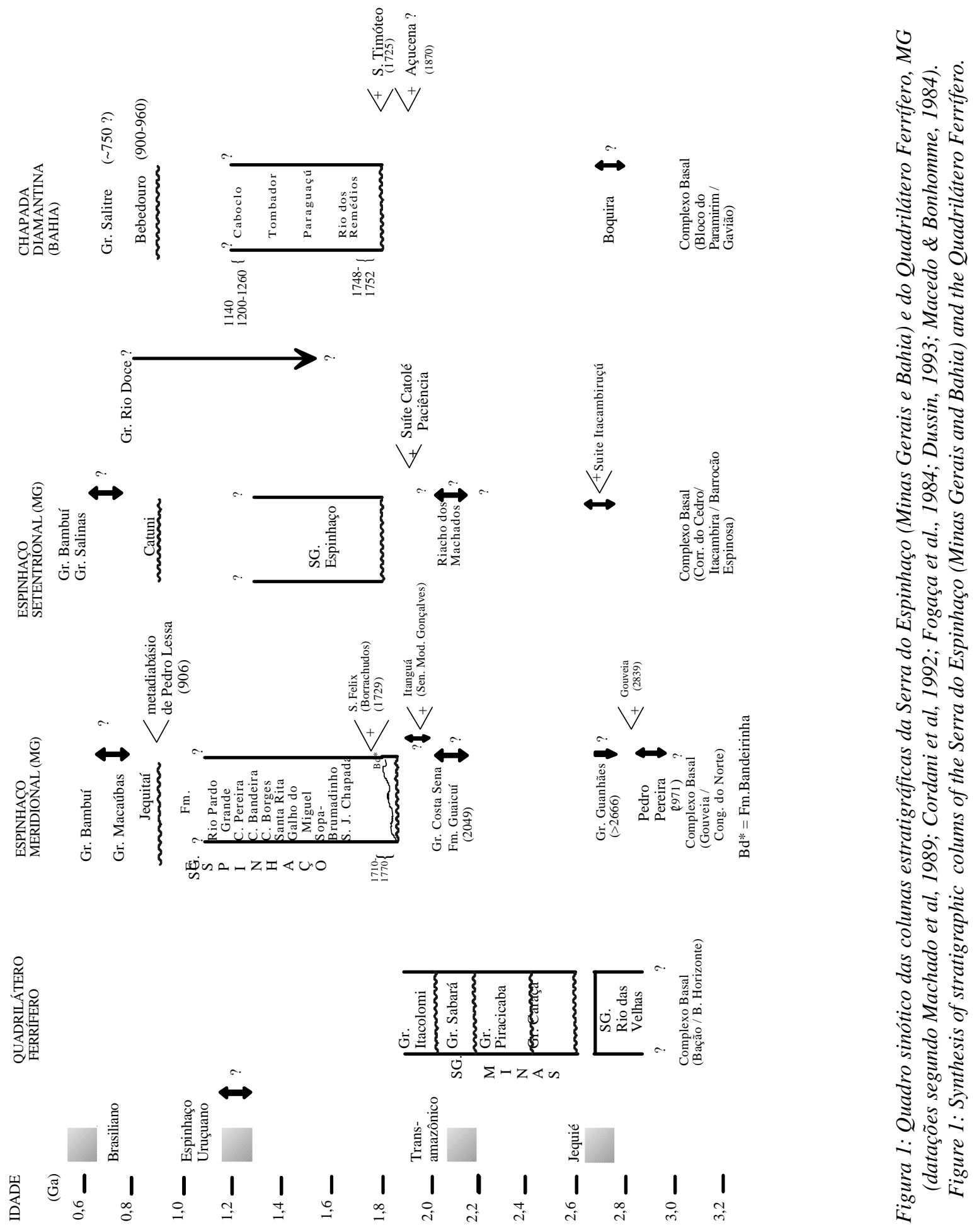


1973, no chamado Supergrupo São Francisco), nem para leste, região chave de muitas das controvérsias geológicas de Minas Gerais. Para tentar facilitar a compreensão das modificações posteriores, cada conjunto maior será discutido em separado, a seguir.

\section{Terrenos gnáissicos/graníticos/migmatíticos}

Estas rochas, correspondentes ao Supergrupo PréRio das Velhas de Schöll \& Fogaça (1979), foram separadas em dois conjuntos por Hoffmann (1981, 1983a), sendo um gnáissico/migmatítico (Grupo Congonhas) e outro granítico (Grupo Gouveia). Datações mais recentes no conjunto granítico (Machado et al., 1989) forneceram idades de $2839 \pm 14 \mathrm{Ma}(\mathrm{U}-\mathrm{Pb}$

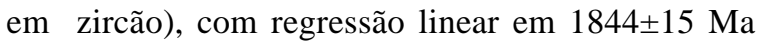
(valor interpretado como de evento tectonometamórfico que afetou o conjunto). A unidade, que corresponde ao Complexo de Gouveia do Projeto Espinhaço, encontra-se afetada por processos de milonitização de diferentes intensidades, os quais são discutidos mais detalhadamente em Schöll \& Fogaça (1981), Fogaça (1982) e Carvalho (1982).

\section{Seqüência Vulcano-Sedimentar Pré-Espinhaço}

Englobado no Supergrupo Rio das Velhas por Schöll \& Fogaça (1979) e no Grupo Costa Sena por Hoffmann (1983b), este conjunto foi redefinido por Fogaça et al. (1984) com a designação de Supergrupo Rio Paraúna. A seção mais basal, com metavulcânicas (ácidas, básicas e ultrabásicas) e metassedimentos dominantemente químicos, foi denominada Grupo Pedro Pereira (redefinição parcial da seqüência informal estudada por Carvalho 1982), apresentando complexa estruturação e características similares a de um greenstone belt. Idades $\mathrm{U}-\mathrm{Pb}$ em zircões de metavulcânicas ácidas deste grupo alcançam valores de 2971 $\pm 16 \mathrm{Ma}$ (Machado et al. 1989), confirmando um posicionamento arqueano.

Entretanto, a seqüência amplamente dominante estaria representada pelo Grupo Costa Sena (Fogaça et al.1984), superior, subdividido nas formações Barão do Guaicuí e Bandeirinha. A Formação Barão do Guaicuí é dominantemente xistosa, prevalecendo rochas com quartzo e sericita/moscovita, apresentando quantidades variáveis de turmalina, cianita e/ou lazulita/ augelita (fosfatos caracterizados por Hoffmann 1980), com reduzidas quantidades de quartzitos micáceos, formação ferrífera bandada, clorita xistos e metavulcânicas ácidas. Estas últimas foram datadas por Machado et al. (1989) através de método U-Pb em zircões, obtendo-se idades de 2049+3/-2 Ma. Alguns trabalhos mais recentes sugerem que a maior parte destas rochas correspondam a milonitos das rochas graníticas/gnaissicas (Dossin et al. 1990), eventualmente originadas durante processos de extensão (Almeida-Abreu 1993); outros autores (e.g. Fogaça et al. 1985) defendem a integridade total da unidade, esquema também adotado pelo Projeto Espinhaço.
A segunda formação deste grupo (Bandeirinha), de extensão em área e espessura algo mais reduzida, é também motivo de controvérsias. O posicionamento dos quartzitos e metaconglomerados da unidade dentro do Grupo Costa Sena é aceito por alguns (e.g. Knauer 1990), em vista dos contatos aparentemente gradacionais com rochas da Formação Barão do Guaicuí. Outros pesquisadores têm defendido um posicionamento basal dentro do Supergrupo Espinhaço (e.g. Almeida-Abreu 1993), reativando, de certo modo, as idéias de Gorlt \& Renger (1972). Silva (1995), que também advoga um posicionamento na base do Espinhaço, reconheceu três seqüências deposicionais no conjunto correspondente à formação, denominadas de Basal (metapelitos, metachert's e BIF), Olaria e Natureza.

\section{Supergrupo Espinhaço}

Em termos estratigráficos, as oito formações originais definidas por Pflug (1968) foram englobadas por Dossin et al. (1984) nos grupos Diamantina (formações São João da Chapada, Sopa-Brumadinho e Galho do Miguel) e Conselheiro Mata (formações Santa Rita, Córrego dos Borges, Córrego da Bandeira, Córrego Pereira e Rio Pardo Grande). Considerando inclusive o extensivo uso do termo Diamantina com os mais diferentes significados na literatura sobre a região, Knauer (1990) sugere uma divisão em três conjuntos : Grupo Guinda, Formação Galho do Miguel e Grupo Conselheiro Mata. Para Almeida-Abreu (1993), entretanto, o Grupo Guinda incluiria não só as formações São João da Chapada e Sopa-Brumadinho, mas também as formações Bandeirinha, na base, e Galho do Miguel, no topo.

A formalização dos níveis anteriormente sugeridos por Schöll \& Fogaça (1979) foi realizada apenas para aqueles relacionados à Formação Sopa-Brumadinho : D (Membro Datas, Almeida-Abreu 1993), E (Membro Caldeirões, Almeida-Abreu, 1993) e F (Membro Campo Sampaio, Fogaça \& Almeida-Abreu 1982). Deve-se notar que esta divisão em membros ou níveis tem caráter ainda local, não sendo aplicável, por exemplo, em terrenos da porção setentrional da serra.

$\mathrm{Na}$ borda leste da serra afloram, claramente relacionadas ao Supergrupo Espinhaço, rochas subvulcânicas até vulcânicas ácidas metamorfisadas em baixo grau, estudadas com algum detalhe por Renger (1970), Herrgesell (1984), Dossin (1985) e Tagliani et al. (1988). Os valores geocronológicos iniciais obtidos por Brito Neves et al. (1979) para estas rochas (por volta de 1770 milhões de anos) foram recentemente confirmados por Machado et al. (1989), através de método U-Pb em zircões, os quais obtiveram idades de 1711+8/-4 Ma. e 1715 \pm 2 Ma.. É interessante notar que mais a norte, as mesmas rochas forneceram idades mais antigas, por volta de $1752 \pm 2 \mathrm{Ma}$. em Planalto de Minas (Machado et al., 1989).

Além dos metassedimentos e das meta-ígneas ácidas, são algo característicos os xistos verdes e filitos 
hematíticos, algumas vezes mostrando transições entre si. Estes últimos, com composição peculiar, foram considerados como tufitos básicos até ultrabásicos (Schöll \& Fogaça 1981), como meta-ígneas alcalinas (Herrgesell 1984; Dussin et al. 1994) ou até mesmo como "vulcânicas intrusivas" (Chaves 1987). Por outro lado, Knauer (1990) e Knauer \& Schrank (1993) propõem que estas rochas resultaram do metamorfismo dos produtos de alteração superficial sobre rochas básicas (eventualmente constituindo verdadeiros paleosolos) e, localmente (região de Itapanhoacanga, estudada por Paternoster 1979), ácidas. Representariam, portanto, pelo menos em parte, lateritas e bauxitas (para rochas ricas em cloritóide) do Mesoproterozóico, metamorfisadas em baixo grau. Estes filitos hematíticos tiveram zircões tratados por metodologia $\mathrm{Pb}-\mathrm{Pb}$ (Dossin et al. 1993), fornecendo idade de 1710 $\pm 12 \mathrm{Ma}$.

\section{Seqüências da Borda Leste}

A chamada "borda leste" da Serra do Espinhaço Meridional tem sido objeto de frequientes trabalhos, especialmente de cunho estrutural e/ou estratigráfico (e.g. Assis 1982; Uhlein 1982; Assis \& Marini 1983; Herrgesell 1984, 1985; Dossin 1985; Almeida-Abreu et al. 1989; Almeida-Abreu 1993), mas as polêmicas e controvérsias ainda persistem. Além de conjuntos granito/gnáissicos de idade arqueana (e.g. Bastos Neto 1982), afloram ainda seqüências metassedimentares e/ ou meta-ígneas de posicionamento discutível, interpretadas de maneira variável de autor para autor. Um exemplo disto é o de que mesmo quartzitos, metaconglomerados e filitos hematíticos normalmente incluídos no Supergrupo Espinhaço, foram englobados por Soares $\mathrm{F}^{\circ}$ et al. (1986) na Seqüência VulcanoSedimentar Conceição do Mato Dentro, considerada por este autor, de idade paleoproterozóica.

Tradicionalmente, duas outras seqüências são reconhecidas (Dossin et al. 1984): uma itabirítica/ quartzítica/filítica (Seqüência Itabirítica de Uhlein 1982, e de Assis 1982) e outra predominantemente meta-ultramáfica (Seqüência Vulcano-Sedimentar de Serro, Uhlein 1982). A primeira, normalmente correlacionada ao Supergrupo Minas do Quadrilátero Ferrífero (e.g. Assis \& Marini 1983), foi estudada em seu setor mais meridional por Dossin (1985), que propõe a designação "Sequiência Itabirítica da Serra da Serpentina" (e que corresponde ao Grupo Serra da Serpentina de Grossi-Sad \& Magalhães 1989). Mais a norte, a "Seqüência Itabirítica" foi dividida em duas unidades tectono-estratigráficas por Almeida-Abreu et al. (1989), denominadas Seqüência Itapanhoacanga e Seqüência Serra do Sapo, consideradas como resultantes do desenvolvimento no Mesoproterozóico da Bacia Espinhaço.

A seqüência predominantemente meta-ultramáfica, típica da região do Serro, foi considerada, em conjunto com metassedimentos químicos e clásticos aflorantes a sul do Serro, como um greenstone belt de idade arqueana por Uhlein (1982). Um caráter ofiolítico, já em parte proposto por Renger (1970), tem sido defendido por Fogaça (1985) e Almeida-Abreu \& Pflug (1994). Estudos recentes sobre as fases minerais e sobre as mineralizações de cromita estão sendo desenvolvidos por Zaparolli (em preparação). Para os metassedimentos considerados como pertencentes à seqüência por Assis (1982), Knauer (1990) sugere a designação ainda informal de Unidade Zagaia, considerando-a como resultante do desenvolvimento do Supergrupo Espinhaço. Estas mesmas rochas, com uma concepção evolutiva similar, mas com distribuição mais ampla, foram denominadas por Almeida-Abreu et al. (1989) de Seqüência Jacém.

\section{SEDIMENTOLOGIA}

Sem duvida, os estudos sedimentológicos mais modernos na Serra do Espinhaço Meridional mostram uma clara influência inicial do trabalho de Schöll \& Fogaça (1979). Estes autores definiram o predomínio de um ambiente marinho raso para a origem das rochas hoje englobadas na Formação Bandeirinha, ambientes fluviais até marinhos rasos para a deposição da Formação São João da Chapada e ambientes marinhos diversificados (mas fundamentalmente não profundos) para as restantes unidades do Supergrupo Espinhaço (ver também Schöll 1980, e Schöll \& Turinsky 1980). Este ambiente marinho para as formações superiores (isto é, Grupo Conselheiro Mata) é confirmada por Garcia \& Uhlein (1987) e por Almeida-Abreu (1993).

O caráter predominantemente marinho para as rochas da Formação Bandeirinha tem sido questionado nos últimos anos (e.g. Knauer 1990). Os principais estudos sobre a unidade são atribuíveis a Silva (1994, 1995), que caracteriza para a maior parte do conjunto, ambientes fluviais com algum retrabalhamento eólico, inclusive com desenvolvimento de típicos red beds.

Os metassedimentos da Formação São João da Chapada, fluviais, tiveram essa interpretação ampliada por Garcia \& Uhlein (1987), o que é confirmado por Martins-Neto (1989, 1992, 1993), entre outros. Os ambientes dominantes para a deposição das rochas da Formação Sopa-Brumadinho têm mostrado uma amplitude não imaginada inicialmente (ver, por exemplo, Almeida-Abreu et al. 1987). Uma transgressão marinha na base da unidade (ou seja, Membro Datas) foi definida por Schöll \& Fogaça (1979), com o que não concordam Almeida-Abreu \& Pflug (1994), que situam estas rochas na sua "fácies lacustre inferior".

Para o Membro Caldeirões (ou Nível E) AlmeidaAbreu \& Munhoz (1983) sugerem, pelo menos localmente, ambientes fluviais até marinhos rasos, relacionando os depósitos conglomeráticos (já estudados por Brichta 1981) a ambientes deltaicos (o que havia sido sugerido, a leste, por Paternoster 1979). O caráter predominantemente fluvial é confirmado por Garcia \& Uhlein (1987), Almeida-Abreu (1993) e Martins-Neto (1993), se bem que um ambiente marinho 
raso, local, é reafirmado em Fogaça et al. (1985).

O Membro Campo Sampaio foi considerado por Fogaça \& Almeida-Abreu (1982) como proveniente da deposição em ambientes relacionados a planícies de marés, com apresentação de detalhadas descrições de suas litologias e estruturas primárias. Recentemente, Almeida-Abreu (1993) sugere para este mesmo conjunto a inclusão em sua "fácies lacustre superior".

À Formação Galho do Miguel, anteriormente (e.g. Schöll \& Fogaça 1979) relacionada a sedimentação marinha mais profunda, é atribuído um caráter eólico por Dossin (1983) e Dossin et al. (1987). Dentro deste contexto, foram descritas por Köster (1984) associações de metarenitos e metapelitos com níveis de turmalina e com laminações convolutas, que podem ser interpretadas como depósitos do tipo wadi (AlmeidaAbreu 1993).

Para as seqüências típicas da borda leste da serra, os estudos sedimentológicos são ainda incipientes, se bem que dentro de um contexto de evolução da "Bacia Espinhaço", admite-se que, progressivamente, passem a ocorrer ambientes cada vez mais profundos em direção a leste (Almeida-Abreu et al. 1989). Depósitos de características francamente turbidíticas podem estar preservados localmente (e.g. Knauer 1990).

\section{MAGMATISMO BÁSICO}

Um dos grandes problemas da evolução da chamada "Bacia Espinhaço" sempre foi o da falta de representantes vulcânicos básicos importantes em suas unidades inferiores, se bem que exemplos locais tenham sido relatados (e.g. Hoppe 1978; Schöll \& Fogaça 1981; Paternoster 1979; Fogaça et al. 1985). Uma hipótese para esta carência é o de sua não preservação graças a processos de alteração superficial, esperados no estágio de evolução da bacia onde os derrames seriam típicos (Knauer 1990).

Além disso, recentemente foi proposto que a maior parte dos xistos verdes anteriormente considerados como típicos do Grupo Macaúbas (e.g. Hettich 1975) representem, em realidade, este vulcanismo básico inicial do desenvolvimento do "Rift Espinhaço" (Knauer 1990). Um estudo detalhado destas rochas na região de Planalto de Minas foi apresentado por Chula (1995), confirmando o posicionamento dos xistos verdes no Supergrupo Espinhaço.

A Serra do Espinhaço, por outro lado, apresenta uma quantidade relativamente grande de diques e sills de rochas básicas, via de regra metamorfisadas na fácies xisto verde. Estes corpos, englobados sob a designação de Suíte Meta-ígnea Deputado Augusto Clementino por Almeida-Abreu et al. (1989) e de Suíte Pedro Lessa no Projeto Espinhaço, foram estudados com algum detalhe por Hoppe et al. (1983) e Silva (1992), entre outros. Datações U-Pb em baddelleyita e zircão destas rochas na região de Pedro Lessa forneceram idades de cristalização de $906 \pm 2$ milhões de anos (Machado et al. 1989).
Por outro lado, corpos intrusivos básicos de idade mais recente, não apresentando sinais de metamorfismo, tem sido descritos na região (e.g. Bastos Neto 1982; Herrgesell 1984; Guimarães 1992). Idades K/Ar apresentadas por Dossin et al. (1993) confirmam o posicionamento Mesozóico já admitido, entre outros, por Herrgesell (1984) e Knauer (1990).

\section{GEOLOGIA ESTRUTURAL}

Trabalhos tratando (exclusivamente ou não) da caracterização estrutural das unidades aflorantes na Serra do Espinhaço Meridional tem sido profusamente publicados nos últimos 16 anos (e.g. Uhlein 1984; Herrgesell 1984; Uhlein et al. 1986; Almeida-Abreu et al. 1986, 1988; Kalt 1991; Rolim 1992). De sua análise, fica claro que a principal controvérsia prende-se ao caráter mono- e policíclico da deformação das rochas do Supergrupo Espinhaço.

Apenas um evento deformacional com transporte de massa de leste para oeste (originalmente definida por Herrgesell 1984 e Almeida-Abreu et al. 1986), de idade Brasiliana, é a hipótese defendida, entre outros, por Dossin et al. (1990), Uhlein (1991) e Trompette et al. (1992). Outros autores (e.g. Knauer 1990; AlmeidaAbreu \& Pflug 1994; Kalt 1991) defendem, entretanto, a atuação de dois grandes eventos aproximadamente coaxiais e relacionados à proximidade da interface Meso- Neoproterozóico e ao Brasiliano (retomando, deste modo, as assertivas originais de Schöll \& Fogaça 1981; Fogaça \& Schöll 1984 e Fogaça et al. 1985).

Os defensores desta última hipótese levam em consideração não apenas os elementos estruturais observados, mas também outros aspectos geológicos maiores. Entre estes destaca-se, sem duvida, o contato entre o Supergrupo Espinhaço e o Grupo Macaúbas, marcado por discordância angular e erosiva (e.g. Köster 1984). Na Folha Presidente Kubitschek (a sul de Diamantina), Kalt (1991) mapeou em detalhe área onde uma falha de empurrão com transporte de leste para oeste está recoberta discordantemente por metadiamictitos do Grupo Macaúbas. Outra evidência é ressaltada por Fogaça (1982), que mostra diques de metabasitos do início do Neoproterozóico cortando alguns planos de falhas de empurrão.

\section{GEOLOGIA ECONÔMICA}

A maior riqueza mineral continua sendo o diamante, mesmo já decorridos 270 anos de explotação ininterrupta. A importância das jazidas dos metaconglomerados da Formação Sopa-Brumadinho e nos ribeirões da serra declinou, e a grande produção atual provém dos aluviões do Rio Jequitinhonha onde o diamante é lavrado por processo de dragagem mecanizada. A origem dos diamantes da Serra do Espinhaço ainda não está completamente esclarecida. Porém, Almeida Abreu (1993) e Fleischer (1993) demonstraram a íntima relação entre o rifting e a 
deposição dos conglomerados diamantíferos. A fase de rifting foi acompanhada de expressiva atividade vulcânica básica e ácida; resta, ainda, identificar com segurança kimberlitos associados. A rocha de um pequeno pipe intrusivo em metaconglomerados da Lavra do Damásio tem composição química similar ã de rochas kamafugíticas-lamproíticas, o que parece reforçar a possibilidade de se detectar kimberlitos. Os filitos hematíticos podem ser, originalmente rochas ultrapotássicas, e formam, eventualmente, consideradas (em parte) como rocha matriz dos diamantes da região (e.g. Herrgesell 1984).

Muitas tem sido as tentativas mais recentes de se descobrir novas jazidas na Serra do Espinhaço e suas adjacências. Bauxita, cromita, minérios de ferro, ouro, quartzo, cianita e fosfato, entre outros, foram pesquisados por empresas ou estudados em trabalhos de cunho acadêmico. Uma das poucas pesquisas que alcançaram sucesso é a do depósito de ouro de Riacho dos Machados (Fonseca 1993).

$\mathrm{Na}$ Serra do Espinhaço e adjacências ocorrem formações ferríferas bandadas (BIFs) de diversas idades (do Arqueano ao Neoproterozóico), a saber nos grupos Guanhães, Pedro Pereira, Riacho dos Machados, Costa Sena, Serra da Serpentina, Guinda (Formação Itapanhoacanga) e Macaubas (Formação Nova Aurora). Mesmo as ocorrências que exibem depósitos de maior volume não podem concorrer, no momento, com as jazidas do Quadrilátero Ferrífero. Porém oferece-se aqui um novo campo de estudos comparativos entre estas formações ferríferas, que contemplam um amplo espectro ambiental, tendo em vista que se reconhecem exemplos dos tipos Algoma, Superior e Rapitan.

Quartzo é lavrado em muitos lugares na serra para produção de lasca de alta pureza e para uso metalúrgico. Os depósitos do sul de Gouveia foram estudados com algum detalhe por Carvalho (1982).

Bauxita e cromita ocorrem em jazidas de pequena tonelagem o que, aliado às grandes distâncias, dificulta a sua viabilização econômica. Fosfato de origem sinsedimentar (apatita) no Membro Campo Sampaio foi identificado por Fritzsons \& Nassif (1992) ao longo de uma extensa faixa nos arredores de Conceição de Mato Dentro, cujos depósitos, aparentemente sem um maior interesse econômico maior, foram estudados recentemente por Mourão (1995).

Uma síntese mais abrangente sobre o potencial de recursos minerais da Serra do Espinhaço e áreas adjacentes encontra-se em Scliar (1995; neste volume).

\section{CORRELAÇÃO COM A CHAPADA DIAMANTINA}

Dispõe-se hoje de boas datações da base das seqüências sedimentares do Espinhaço tanto em Minas Gerais como na Bahia que se correlacionam com a fase de abertura do rift (ao redor dos 1800 milhões de anos). Para o topo das sequiências tem-se datações de menor precisão que permitem atribuir uma idade ao redor de
1100 a 1200 Ma (Macedo \& Bonhomme 1984; Babinski et al. 1993).

A Formação Caboclo da Chapada Diamantina apresenta litologias muito semelhantes às da Formação Rio Pardo Grande do Supergrupo Espinhaço, na Serra do Espinhaço Meridional de maneira que sua correlação foi proposta por Schobbenhaus (1993) enquanto Uhlein (1991) sugere sua correlação genérica com o Grupo Conselheiro Mata.

\section{MODELOS EVOLUTIVOS}

Os modelos evolutivos para os terrenos constituintes da Serra do Espinhaço Meridional, em especial durante o Pré-Cambriano (ou melhor, Pré-Siluriano) mostram progressivamente a incorporação de concepções geotectônicas advindas da tectônica de placas. Se bem que mais explícito a partir da década de oitenta, devese enfatizar que Pflug (1976) já propõe este tipo de abordagem, interpretando a evolução da região como a de uma margem continental passiva.

Por outro lado, modelos baseados em resultados geocronológicos são estimulados fortemente a partir do trabalho de Brito Neves et al. (1979), os quais já definem idades próximas a interface Paleo/ Mesoproterozóico para o início da "Bacia Espinhaço". Segundo estes autores, a evolução da região poderia ser sumarizada nos seguintes períodos: a)2,8-2,6 Ga., com formação do embasamento; b) 2,1-2,0 Ga., com formação de granitos; c) 1,8-1,7 Ga., início de individualização dos sítios de deposição do Espinhaço; d) 1,7-1,3 Ga., com o desenvolvimento da sedimentação cíclica do Supergrupo Espinhaço; e) 1,3-1,2 Ga., representando a principal fase de deformação e metamorfismo; f) 1,2-1,0 Ga., período marcantemente pós-tectônico, com acentuado magmatismo básico e início de individualização da Bacia Bambuí e g) 0,650,50 Ga., com dobramento e metamorfismo não generalizado do Grupo Bambuí e cronocorrelatos. Dados geocronológicos mais recentes (e.g. Machado et al. 1989; Dossin et al. 1994) confirmam pelo menos parte deste modelo.

Não é objetivo deste trabalho uma discussão aprofundada dos modelos aparecidos nas décadas de oitenta e noventa, os quais podem ser exemplificados por Fogaça (1985), Herrgesell (1984, 1985), Knauer (1990), Uhlein (1991) Uhlein et al. (1995), AlmeidaAbreu (1993,1995) e Dussin \& Dussin (1995). De qualquer modo, algumas considerações básicas merecem destaque:

a) $\mathrm{O}$ desenvolvimento das porções basais do Supergrupo Espinhaço em ambiente de rift é, atualmente bem aceito (e.g. Almeida-Abreu \& Pflug 1994; Dussin \& Dussin 1995), tendo sido enfaticamente sugerido por Pflug et al. (1980) e Torquato \& Fogaça (1981);

b) A evolução deste rift inicial para uma margem passiva, já no Mesoproterozóico, não aceita por alguns (e.g. Uhlein 1991), tem sido proposta, envolvendo pelo 
menos parte das seqüências aflorantes na borda leste da serra (e.g. Herrgesell 1985; Almeida-Abreu et al. 1989);

c) O desenvolvimento de crosta oceânica durante a evolução mesoproterozóica é sugerido por alguns pesquisadores, incluindo Fogaça (1985), AlmeidaAbreu et al. (1989) e Almeida-Abreu \& Pflug (1994).

\section{COMENTÁRIOS FINAIS}

A ligeira compilação apresentada anteriormente, e que seguramente não envolve todos os trabalhos publicados no período (não considerando, por exemplo, aqueles relacionados mais diretamente com as sequiências do Neoproterozóico), demonstra claramente a importância da região para os estudos geológicos. Ao mesmo tempo, em que pese a enorme quantidade de dados e interpretações produzidos no período, alguns pontos permanecem polêmicos ou mesmo obscuros. Estes pontos deveriam, na opinião dos autores, constituirem-se em objetos de estudos mais definitivos no futuro, incluindo os seguintes:

a) Caracterização estrutural detalhada das principais seqüências aflorantes na região, visando a definição dos eventos atuantes durante o período Arqueano Brasiliano, em especial da comprovação ou não de um Evento "Uruaçuano/Espinhaço";

b) Tentativa de posicionamento estratigráfico das seqüências da borda leste, ainda controverso, visando o estabelecimento de padrões evolutivos mais confiáveis;

c) Caracterização estratigráfica, petrográfica e geoquímica das formações ferríferas bandadas, visando a confirmação ou não do diversificado posicionamento estratigráfico em relação as unidades existentes;

d) Caracterização e comparação das seqüências predominantemente meta-ultramáficas, em especial aquelas relacionadas ao Grupo Pedro Pereira, ao Grupo Serro e as ocorrências da região de Morro do Pilar;

e) Detalhamento nos estudos em rochas do Grupo Conselheiro Mata, inclusive com determinações geocronológicas $\mathrm{Pb}-\mathrm{Pb}$ nas intercalações carbonáticas da Formação Rio Pardo Grande;

f) Investigação geoquímica, incluindo isótopos (Nd$\mathrm{Sr}$ e $\mathrm{Pb}$ ), das rochas metavulcânicas ultrabásicas, básicas e ácidas das unidades Pedro Pereira e Costa Sena, das metabásicas “iniciais”do rift Espinhaço e das metabásicas pós-Espinhaço (Suite Pedro Lessa);

g) Estabelecimento de critérios (possivelmente geoquímicos) para separar, em definitivo, materiais considerados produtos de milonitização de granitos, de micaxistos Costa Sena, originados de pelitos;

h) Investigação da origem dos "filitos hematíticos", possivelmente com uso de isótopos radiogênicos (Nd$\mathrm{Sr}$ e $\mathrm{Pb}$ );

i) Estudo comparativo, petrográfico e geoquímico, das unidades do Complexo Basal presentes no interior da Cordilheira e em seu bordo leste (faixas de Gouveia - Itacolomi e Serro - Alvorada de Minas - São Sebastião do Rio Preto);

j) Retomada dos estudos de geologia econômica, envolvendo trabalho sistemático sobre ouro e platinoides, incluindo mapeamento detalhado das ocorrências e antigos jazimentos;

k) Estudos de tectônica global, utilizando não só análise de bacias, mas, principalmente, as relações do magmatismo com processos da tectônica global;

1) Estudos geocronológicos regionais sobre metabasitos e metariolitos-metadacitos, visando estabelecer a evolução do rift Espinhaço.

\section{AGRADECIMENTOS}

Os autores agradecem a J.H. Grossi Sad pela revisão criteriosa e pelas valiosas sugestões.

\section{REFERÊNCIAS BIBLIOGRÁFICAS}

Almeida Abreu, P.A. 1993. A evolução geodinâmica da Serra do Espinhaço Meridional, Minas Gerais, Brasil. - Tese de Doutoramento, Univ. Freiburg/Alemanha, 150 p.

Almeida Abreu, P.A. 1995. O Supergrupo Espinhaço da Serra do Espinhaço Meridional (Minas Gerais. o Rifte, a Bacia e o Orógeno. - Geonomos, 3/1 (neste volume)

Almeida Abreu, P.A. \& Munhoz, D.T.V. 1983: A reconstituição paleogeográfica e o estudo dos minerais pesados como indicativos de áreas fontes primárias dos diamantes da Serra do Espinhaço, Minas Gerais. - 2. Simp. Geol. Minas Gerais, Anais, SBG/MG, Bol. 3, p. 219234

Almeida Abreu, P.A., Fernandes, P.C. de O., Knauer, L.G., Hartmann, M.B., Donato, M.T.R. \& Schorscher, H.D. 1986. Elementos da zona de cisalhamento dúctil da borda oriental da Serra do Espinhaço Meridional, Minas Gerais. - 34. Congr. Bras. Geol., Goiânia, Anais, vol. 2, p. 1219 - 1236

Almeida Abreu, P.A., Fogaça, A.C.C., Knauer, L.G., Hartmann, M.B. \& Pflug, R. 1987. Revisão da estratigrafia e sedimentologia da Formação Sopa-Brumadinho na Serra do Espinhaço Meridional, Minas Gerais. - Simp. Sistem. Depos. Precambr., SBG/MG, Bol. 6, p. 85 - 96

Almeida Abreu, P.A., Knauer, L.G., Hartmann, M.B., Vieira dos Santos, G.G., Guimarães, M.L.V., Abreu, F.R., Schrank, A \&Pflug, R. 1989. Estratigrafia, facilogia e tectônica do Supergrupo Espinhaço na região de Serro - Conceição do Mato Dentro, Minas Gerais. - Zbl. Geol. Paläont., Teil I, 1989, (5/6), p. $857-873$

Almeida Abreu, P.A. \& Pflug, R.1994. The geodynamic evolution of the southern Serra do espinhaço, Minas Gerais, Brazil. - Zbl. Geol. Paläont., Teil I, 1993, 1/2), p. 21 - 44

Assis, L.C. 1982. Estratigrafia, tectônica e potencialidade mineral das unidades precambrianas da região de Serro - MG (Quadrícula Mato Grosso). - Dissertação de Mestrado, Univ Brasília, 149 p.

Assis, L.C. \& Marini, O.J. 1983. Contribuição à controvérsia da correlação Espinhaço - Minas. - 2. Simp. Geol. Minas Gerais, Anais, SBG/MG, Bol. 3, p. $361-375$

Babinski, M., van Schmus, W.R., Chemale Jr., F., Brito Neves, B.B. \& Rocha, A.J.D. 1993. Idade isocrônica $\mathrm{Pb} / \mathrm{Pb}$ em rochas carbonáticas da Formação Caboclo, em Morro do Chapéu, BA. - II Simp. sobre o Craton São Francisco, Salvador, Anais, p. $160-163$

Bastos Neto, A.C. 1982. Geologia das quadrículas Dom Joaquim e parte sul da Ribeirão da Barra - borda leste da Serra do Espinhaço Meridional, MG. - Dissertação de Mestrado, UFRJ, $111 \mathrm{p}$.

Brichta, A. 1981. Zur Sedimentologie und Genese der diamantführenden Konglomerate von Diamantina, Minas Gerais (Unteres Proterozoikum, Ostbrasilien). - Tese de Doutoramento, Univ. Freiburg/Alemanha, 48 p. 
Brito Neves, B.B., Kawashita, K., Cordani, U.G. \& Delhal, J. 1979. A evolução geocronológica da Cordilheira do espinhaço; dados novos e integração. - Rev. Bras. Geocienc., 9, p. 71 - 85

Carvalho, A. de S. 1981. Geologia e gênese das mineralizações de quartzo no Espinhaço Meridional, MG. - Dissertação de Mestrado, UnB, Brasília, 52 p.

Chaves, M.L. de S.C. 1987.Novas contribuições à geologia da região de Diamantina (MG). - 4. Simp. Geol. Minas Gerais, Anais, SBG/MG, Bol. 7, p. 72 - 87

Chula, A.M.D. 1995. Caracterização e geoquímica dos metamagmatitos e metassedimentos da região de Planalto de Minas, Município de Diamantina, MG. - Sem. de Qualificação do curso de Pósgraduação, IGC, UFMG, 142 p.

Cordani, U.G., Iyer, S.S., Taylor, P.N., Kawashita, K., Sato, K \& McReath, I. 1992. Pb-Pb, Rb-Sr, and K-Ar systematics of the Lagoa real uranium province (south-central Bahia, Brazil) and the Espinhaço Cycle (ca. 1.5 - $1.0 \mathrm{Ga}$ ). - J. South Amer. Earth Sc., 5, p. $33-46$

Dossin, I.A. 1983. Geologia, gênese e controle dos depósitos de manganês associados ao Grupo Macaúbas na borda ocidental da Serra do Cipó - MG (área do Inhame). - Dissertação de Mestrado, UnB, Brasília, 127 p.

Dossin, T.M. 1985.Geologia e geoquímica ads formações ferríferas da Serra da Serra da Serpentina, Conceição do Mato Dentro. Dissertação de Mestrado, UnB, Brasília,

Dussin, I.A. 1994. Evolution structurale de la region de l'Espinhaço Meridional, bordure sud-est du Craton São Francisco, Brésil. Tese de Doutoramento, Univ. Orléans, 200 p

Dossin, I.A. \& Dardenne, M.A. 1984. Geologia da borda ocidental da Serra do Cipó. Minas Gerais (Área do Inhame). - 33. Congr. Bras. Geol., Anais, Vol. 7, p. 3104 - 3117

Dossin, I.A., Uhlein, A. \& Dossin, T.M. 1984. Geologia da faixa móvel Espinhaço em sua porção meridional, MG. - 33. Congr. Bras. Geol. (Rio de Janeiro), Anais, vol. 7, p. 3118 - 3132

Dossin, I.A., Garcia, A.J.V., Uhlein, A., Dardenne, M.A. \& Dossin, T.M 1987. fácies eólico na Formação Galho do Miguel, Supergrupo Espinhaço (MG). - Simp. Sistem. Depos. Precambr. Anais, SBG/MG, Bol. 6, p. 85 - 96

Dossin, I.A., Dossin, T.M. \& Chaves, M.L. de S.C. 1990 Compartimentação estratigráfica do Supergrupo Espinhaço em Minas Gerais - Os grupos Diamantina e Conselheiro Mata. Rev. Bras. Geocienc.., 20 (1-4), p. 178 - 186

Dussin, I.A., Dossin, T.M, Charvet, J., Cocherie, A. \& Rossi, P 1993. Single zircon dating by step-wise Pb-evaporation of Middle Proterozoic magmatites in the Espinhaço Range, southeastern São Francisco Craton (Minas Gerais, Brazil) - II Simp. Craton São Francisco, Anais, p. 39 - 42

Dussin, T.M., Dussin, I.A., Rossi, P. \& Charvet, J. 1994. Dating of the Mesoproterozoic tensional event in the Espinhaço Range, Southeastern of the São Francisco Craton (SE Brazil). in: Dussin, I.A.: Evolution structurale de la region de l'Espinhaço Meridional, bordure sud-est du craton São Francisco, Brésil. Tese de Doutoramento, Univ. Orléans, p. 105 - 133

Dussin, I.A. \& Dussin, T.M. 1995. Supergrupo Espinhaço: Modelo de evolução geodinâmica. - Geonomos, 3/1 (neste volume)

Fleischer, R. 1993. Um modelo "Rift" para os depósitos sedimentares de diamante do Brasil. I Simp. Bras. Geol. Diamante, Cuiabá, MT, Anais, p. 165 - 197

Fogaça, A.C.C. 1982. Geologia e mineralizações auríferas na região de Costa Sena: uma abordagem preliminar. - Inst. Geociências, UnB, $28 \mathrm{p}$

Fogaça, A.C.C. \& Almeida Abreu, P.A.1982. Depósitos de planícies de marés na Formação Sopa-Brumadinho (Proterozóico Inferior), Cordilheira do Espinhaço, Estado de Minas Gerais, Brasil. - V Congr. Latinoamer. Geol., Actas, p. 373 - 388.

Fogaça, A.C.C., Almeida Abreu, P.A. \& Schorscher, H.D. 1984 Estratigrafia da seqüência supracrustal arqueana na porção mediana central da Serra do Espinhaço, MG. - 33. Congr. Bras. Geol., Anais, Vol. 6, p. 2652 - 2667

Fogaça, A.C.C., Martins Neto, M.A. \& Costa, N.B.O.R. 1985. Comportamento faciológico das rochas quartzíticas da Formação Sopa-Brumadinho (Nível E) na região de Costa Sena - 3. Simp. Geol. Minas Gerais, SBG/MG, Bol. 5, p. 112 - 124

Fonseca, E. 1993. Depósito aurífero de Riacho dos Machados, norte de Minas Gerais: Hidrotermalismo, deformação e mineralização associados. - Dissertação de Mestrado, UFMG, 179 p.

Frank, R, 1971. Geologie der nördlichen Serra Mineira aufgrund einer Kartierung 1:50.000 (Südliche Espinhaço Kordillere, Minas Gerais, Brasilien). - Diplom-Arbeit, Univ. Heidelberg, $42 \mathrm{p}$

Fritzsons Jr., O. \& Nassif, M. 1992. A distribuição areal das rochas do Membro Campo Sampaio entre os municípios de Presidente Kubitschek e Bom Jesus de Amparo, Espinhaço Meridional. 6. Simp. Geol. Minas Gerais; Rev. Esc. Minas, vol. 45, p. 105 $-108$

Garcia, A.J.V. \& Uhlein, A. 1987. Sistemas deposicionais do Supergrupo Espinhaço na região de Diamantina MG). - Simp. Sistemas Depos. no Precambr. (Ouro Preto); SBG/MG, Bol. 6, p. $113-136$

Gorlt, G. \& Renger, F. 1972. Levantamento geológico dos conglomerados da Formação Sopa-Brumadinho, Supergrupo Minas, na região de São João da Chapada -Sopa-Guinda, Município de Diamantina na escala 1:10.000. - Inst. Eschwege/ CNEN (Rel. inédito), $16 \mathrm{p}$

Grossi Sad, J.H. \& Magalhães, J.M.M. 1989. Reconhecimento geológico do alto e médio vales do Rio Doce, Minas Gerais, Brasil. - Rel. DOCEGEO/GEOSOL, 154 pp. (inédito)

Grossi Sad, J.H. \& Vaz de Melo, M.T. 1969. Geologia do Distrito do Sêrro, Minas Gerais, Brasil. - Rel. DNPM/GEOSOL, 2 vol., (inédito)

Guimarães, M.L.V. 1992. Petrogênese das rochas Pré-Cambrianas da região Itabira/Morro do Pilar, borda sudeste da Serra do Espinhaço meridional, MG. - Dissertação de Mestrado, USP, $139 \mathrm{p}$.

Hartmann, M.B. 1985. Caracterização da tectônica tangencial e estudo da deformação em metavulcânicas ácidas, Serra do Sapo, borda oriental da Espinhaço Meridional (região Itapanhoacanga - Conceição do Mato Dentro. - Monografia de Especialização, UFRN, $25 \mathrm{p}$

Herrgesell, G. 1984. Das Präkambrium am Ostrand der Serra do Cipó (Serra do Espinhaço, Minas Gerais, Brasilien). - Tese de Doutoramento, Univ. Freiburg/Alemanha, 247 p.

Herrgesell, G. 1985. Uma margem continental proterozóica na Serra do Cipó Setentrional (Serra do Espinhaço Setentrional). - 3. Simp. Geol MG, SBG/MG, Bol. 5, p. 1 - 15

Herrgesell, G. \& Pflug, R. 1986. The thrust belt of the Southern Serra do Espinhaço, Minas Gerais, Brazil. - Zbl. Geol. Paläont., Teil I, 1985 (9/10), p. 1405 - 1414

Hettich, M. 1975. Zur Genese des Macaúbas und Geologie des Gebietes nördlich der Serra Negra Minas Gerais, Brasilien). Geol. Jahrbuch, 14, p. 47 - 85

Hoffmann, C.1980. Neugliederung und geologische Geschichte der "Präminas"-Gesteine in der südlichen Serra do Espinhaço, Minas Gerais, Brasilien. - Münster. Forsch. Geol. Paläont., 51, p. $183-197$

Hoffmann, C.1981. Chi-square testing of zircon-populations from an Archean granite-greenstone terrain, Minas Gerais, Brazil. N. Jb. Miner., Abh., 140, p. 202 - 220

Hoffmann, C. 1983 a.The Archean peraluminous Gouveia Granite. Its structure, geochemistry, and phase petrology (Serra do Espinhaço, Minas Gerais, Brazil). N. Jb. Miner., Abh., 146, p. $359-371$

Hoffmann, C. 1983 b. The Costa Sena Group - an early Proterozoic supracrustal succession and the evolution of the Southern Serra do Espinhaço, Minas Gerais, Brazil. - Zbl. Geol. Paläont, H. 3/ 4, p. $446-458$

Hoppe, A. 1978. Beiträge zur Geologie und Paläogeographie der südlichen Serra do Espinhaço (Minas Gerais, Brasilien). - Tese de Doutoramento, Univ. Freiburg, 102 p.

Kalt, H. 1991. Untersuchungen zur Schertektonik in der südlichen Serra do Espinhaço und im angrenzenden Teil des São Francisco Beckens, Minas Gerais, Brasilien. - Tese de Doutoramento, Univ. Freiburg/Alemanha, $118 \mathrm{p}$

Knauer, L.G. 1990. Evolução geológica do Precambriano da porção centro-leste da Serra do Espinhaço Meridional e metalogênese associada. - Dissertação de Mestrado, Unicamp, 298 p.

Knauer, L.G \& Grossi Sad, J.H. 1994. Geologia da Folha Serro, Minas Gerais. - COMIG/UFMG, Rel. Inédito, 263 p. 
Knauer, L.G. \& Schrank, A. 1994. A origem dos filitos hematíticos da Serra do Espinhaço Meridional, Minas Gerais. - Geonomos, $1 / 1$, p. $33-38$

Köster, H.J.1984. Geologie der nordwestlichen Serra Mineira südöstlich von Buenópolis, Proterozoikum, Serra do Espinhaço, Minas Gerais, Brasilien. - Diplom-Arbeit, Univ. Freiburg/ Alemanha, $85 \mathrm{p}$.

Macedo, M.H. \& Bonhomme, 1984. Contribuição à cronoestratigrafia das formações Caboclo, Bebedouro e Salitre na Chapada Diamantina (BA) pelos métodos Rb-Sr e K-Ar. Rev. Bras. Geocienc., vol. 14, p. $153-163$

Machado, N, Schrank, A., Abreu, F.R., Knauer, L.G. \& Almeida Abreu, P.A. 1989. Resultados preliminares da geocronologia U-Pb na Serra do Espinhaço Meridional. - 5. Simp. Geol MG, Anais, SBG/MG, Bol. 10, p. 171 - 174

Martins Neto, M.A. 1989. Sistemas deposicionais e paleogeografia das formações basais do Supergrupo Espinhaço (São João da Chapada e Sopa-Brumadinho) na região de Diamantina/Costa Sena, Minas Gerais, Brasil - Dissertação de Mestrado, UFBa, $88 \mathrm{p}$.

Martins Neto, M.A. \& Pflug, R. 1992. Zur Stratigraphie und Fazies der unteren Espinhaço Supergruppe im Zentralteil der südlichen Serra do Espinhaço, Minas Gerais, Brasilien. - 13. Geowiss. Lateinamerika Koll., Münster/Alemanha, Abstr.

Martins Neto, M.A. 1993. The sedimentary evolution of a Proterozoic rift basin: the basal Espinhaço Supergroup, southern Serra do Espinhaço, MinasGerais, Brazil. - Freiburger geowiss. Beitr., Bd. 4, 155 p.

Mourão, M.A.A. 1995. A unidade fosfática da Formação SopaBrumadinho, Supergrupo Espinhaço (Região de Conceição do Mato Dentro, Minas Gerais). - Dissertação de Mestrado, UnB, Brasília, 138 p.

Noce, C.M. 1993. Geologia da Folha Curimataí, Minas Gerais. COMIG/UFMG, Rel. Inédito, 50 p.

Paternoster, K. 1979. Faziesverzahnung zwischen diamantführenden Konglomeraten und Bändererzen (BIF) in der südlichen Serra do Espinhaço (Minas Gerais, Brasilien). - Tese de Doutoramento, Univ. Freiburg/Alemanha, 88 p.

Pflug, R. 1965. Die präkambrische Miogeosynklinale der EspinhaçoKordilliere, Minas Gerais, Brasilien. - Geol. Rundschau, Bd. 56 , p. $825-844$

Pflug, R. 1968. Observações sobre a estratigrafia da Série Minas na região de Diamantina, Minas Gerais. - DNPM, DGM, Notas prel. e estudos 142, 20 p.

Pflug, R. 1976. Die Serra do Espinhaço - Ein präkambrischer Kontinentalrand. - 5. Geowiss. Lateinamerika Koll., Clausthal/ Alemanha, Abstr.

Pflug, R. \& Renger, F. 1973. Estratigrafia e evolução geológica da margem do Craton Sanfranciscano. - 27. Congr. Bras. Geol., Anais, vol. 2, p. 5 - 19

Pflug, R., Hoppe, A. \& Brichta, A, 1980. Paleogeografia do Precambriano na Serra do Espinhaço, Minas Gerais. - in: Zeil, W. (ed.). Nuevos resultados de la Investigación geocientífica alemana en Latinoamerica. Proyectos da DFG, Boppard (Boldt), p. $33-43$

Renger, F. 1970. Fazies und Magmatismus der Minas Serie in der südlichen Serra do Espinhaço, Minas Gerais, Brasilien. - Geol. Rundschau, vol. 59, p.1253 - 1292

Renger, F. 1972. As rochas ultrabásicas da Serra do Espinhaço, M.G. - Rev. Bras. Geocienc., 2, p. 151 - 160

Renger, F. 1979. Evolução dos conceitos geológicos da Serra do Espinhaço. - 1. Simp. Geol MG, SBG/MG, Bol. 1, p. 9 - 27

Schobbenhaus, C 1993. O Proterozóico Médio no Brasil com ênfase à Região Centro-Leste. - Tese de Doutoramento, Univ. Freiburg/ Alemanha, $166 \mathrm{p}$

Schöll, W.U. 1980. Estratigrafia, sedimentologia e paleogeografia na região de Diamantina (Serra do Espinhaço, Minas Gerais, Brasil). - Münster. Forsch. Geol. Paläont., 51, p. 223 - 240

Schöll, W.U. \& Turinsky, F. 1980. O espectro dos minerais pesados nas seqüências quartzíticas pré-cambrianas na parte sul da Serra do espinhaço, Minas Gerais, Brasil. - Münster. Forsch. Geol. Paläont., 51, p. 257 - 278

Schöll, W.U. \& Fogaça, A.C.C. 1979. Estratigrafia da Serra do Espinhaço na região de Diamantina. - 1. Simp. Geol MG, SBG/ MG, Bol. 1, p. 55 - 73

Schöll, W.U. \& Fogaça, A.C.C 1981. Mapeamento geológico das quadrículas Guinda e Gouveia (MG). - Projeto Mapeamento Espinhaço, Conv. DNPM/UFMG, Rel. inédito, 51 p.

Scliar, C. 1995. Dotação mineral, meio ambiente e desenvolvimento no Alto Jequitinhonha. - Geonomos, 3/1 (neste volume)

Silva, A.M. da 1992. Geologia e petroquímica dos enxames de diques máficos do Quadrilátero Ferrífero e Espinhaço Meridional, MG. - Dissertação de Mestrado, UnB,

Silva. R.R. da 1994. Depositional sequences of the rift phase of the Proterozoic Espinhaço Supergroup, in the area between Diamantina and Gouveia, Minas Gerais, Brazil. - 14. Intern. Sedimentol. Congr., Recife, Abstracts, p. G-75 - 76

Silva, R.R. 1995. Sequence stratigraphy and depositional systems of the lower Espinhaço Supergroup in the region between Diamantina and Gouveia, Minas Gerais, Brazil. - Tese de Doutoramento, Univ Freiburg/Alemanha, em preparação

Siga Jr., O. 1986. A evolução geotectônica da porção nordeste de Minas Gerais, com base em interpretações geocronológicas. Dissertação de Mestrado, USP, 140 p.

Soares Filho, B.S., Pinheiros, S. de O. \& Costa, M.N. de S. 1986 Contribuição ao estudo da geologia da região de Conceição do Mato Dentro. - 34. Congr. Bras. Geol. (Goiânia), Anais, vol. V., p. $1623-1632$

Souza, E.M. \& Martins, M.O.Z. 1995. A Cordilheira do Espinhaço em Minas Gerais: um levantamento bibliográfico. - 8. Simp. Geol. Minas Gerais, Anais (no prelo)

Sperber, M. von 1975. Geologie am Süd-West-Rand der Serra do Cipó (Serra do Espinhaço, Minas Gerais, Brasilien). - Tese de Doutoramento, Univ. Freiburg/Alemanha, 79 p.

Tagliani, T.R., Hartmann, M.B., Almeida Abreu, P.A. \& Fernandes, P.C. de O. 1988. Estudo da deformação em metavulcanitos ácidos da Serra do Sapo, Cordilheira do Espinhaço Meridional, MG. - Rev. Bras. Geocienc., 18, p. 63 - 68

Torquato J.R.F. \& Fogaça, A.C.C. 1981. Correlação entre o Supergrupo Espinhaço no Brasil, o Grupo Cheloem Angola e as Formações Nosib e Khoabendus da Namíbia. - Simp. Craton do São Francisco, 1, p. 87 - 98.

Trompette, R., Uhlein, A., Egydio Silva, M. \& Karmann, I. 1992 The brasiliano São Francisco Craton revisited (Central Brazil) - J. South Amer. Earth Sc., 6 (1/2), 49 - 57

Uhlein, A. 1982. Geologia e mineralizações de cromita e itabiritos da região de Sêrro, MG. - Dissertação de Mestrado, UnB, 189

Uhlein, A. 1984. Estratigrafia, tectônica e potencialidade mineral da Região de Morro do Pilar, MG. - Relatório de auxílio à pesquisa, $\mathrm{CNPq}, 49 \mathrm{p}$.

Uhlein, A. 1991. Transição craton faixa dobrada: exemplo do Craton São Francisco e da Faixa Araçuaí (Ciclo Brasiliano) no Estado de Minas Gerais. Aspectos estratigráficos e estruturais. - Tese de Doutoramento, USP, $295 \mathrm{p}$.

Uhlein, A., Trompette, R \& Egydio-Silva, M 1995. Rifteamentos superpostos e tectônica de inversão na borda sudeste do Cráton do São Francisco. - Geonomos 3/1, (neste volume)

Zaparolli, A. 1995. Petrografia e geoquímica do depósito de cromita do Morro do Cruzeiro, Sêrro, MG. - Dissertação de Mestrado, UNESP Rio Claro, (em preparação) 
